of about ten different programmes are given daily to the general public. Special programmes at a much higher level are presented in conjunction with navigation, astronomy and other academic courses.

\title{
The Starlab Mobile Planetarium in the Mid-Pyrenees
}

Jean-Pierre Chrétien, Jean-Pierre Brunet

1 allée des Roses, F-31520 Ramonville Saint-Agne, France

This planetarium with inflatable dome is available to schools, colleges and youth centres in the region. Each institution using the equipment provides its own lecturer, supported by various levels of documentation, discussion sessions and alternative displays. In the first year about 50 organisations used it, each for about a week, with some 15000 child, and 6000 adult visitors. No serious problems were encountered despite this intensive use.

\section{The Planetarium at a School in Nice}

\section{Jeanine Chappelet}

Planetarium du collège Valéri, B.P. 86, F-06013 Nice Cedex, France

An observatory, laboratory and planetarium were set up by pupils at a school in Nice with assistance from the Club des Pléiades. Various presentations were given, for children and adults, and some with the assistance of astronomers from the $\mathrm{Ob}$ servatory at Nice for teacher-training.

[Full text not received - Eds.]

\section{The Planetarium as a Medium for Teaching Astronomy}

\section{Kunda Barve}

Planetarium, Nehru Centre, Dr Annie Besant Road, Worli, Bombay 400018 , India

Being sited in a large city (with about 10 million inhabitants), the planetarium at Bombay has to try to meet the requirements of a very wide range of visitors, some 3.3 million of whom have seen presentations. These visitors come from very different linguistic, cultural, religious, economic and educational backgrounds, which pose many problems in arranging suitable programmes. (There are 16 major languages and many less common ones.) School children make up the bulk of visitors and presentations for them are linked to their academic grade. Amateur astronomical organisations are gradually coming into existence in India, and the planetarium provides help and encouragement to them. Special shows are made for many individual groups of people, ranging from lovers of poetry and fine arts to invalids and the handicapped. A wide range of additional activities such as competitions, field trips and exhibitions is also provided. 